\title{
Comparative study of uterine repair during caesarean section: exteriorization repair versus in-situ repair
}

\author{
Lakshmi Priya, Reddi Rani P.*, Lopamudra B.
}

\begin{abstract}
Department of Obstetrics and Gynecology, Mahatma Gandhi Medical College and Research Institute, Pondicherry,
\end{abstract} Tamil Nadu, India

Received: 20 January 2017

Accepted: 06 March 2017

\section{*Correspondence: \\ Dr. Reddi Rani P., \\ E-mail: ranipr50@gmail.com}

Copyright: ( ) the author(s), publisher and licensee Medip Academy. This is an open-access article distributed under the terms of the Creative Commons Attribution Non-Commercial License, which permits unrestricted non-commercial use, distribution, and reproduction in any medium, provided the original work is properly cited.

\section{ABSTRACT}

Background: Cesarean section is one of the most common major obstetrical operation performed worldwide and the rates of cesarean section are increasing. It is associated with both intra-operative and post-operative complications. Many variations in surgical methods have been devised to decrease the adverse effects and morbidity. One such method is technique of uterine repair after delivery of the fetus and placenta by exteriorizing the uterus or in-situ repair.

Methods: A prospective comparative study was conducted in the department of Obstetrics and Gynecology at MGMCRI Pondicherry over 18 months from March 2015 to August 2016. Two hundred women undergoing caesarean section were assigned to 2 groups. Group 1 (Exteriorization) 100 women and Group 2 (In-situ repair) 100 women. Intra-op and post-operative complications were assessed in both groups and compared.

Results: There was no significant difference between the two groups with regard to age, parity, gestational age and type of cesarean section. There was no significant difference between two groups with regard to fall in Hb, operating time, mean drop in pulse rate and blood pressure, nausea, vomiting and intra-op pain. There was significant difference in blood loss during surgery in in-situ repair, $\mathrm{P}$ value was $<0.001$ highly significant and also statistically significant increase in transfusion rates in in-situ group with a $\mathrm{p}$ value of 0.038 . Postoperative complications like febrile morbidity was significantly more in in-situ repair $\mathrm{P}=0.046$. There was no significant difference in other variables like urinary tract infection, surgical site infection, endometritis and hospital stay.

Conclusions: Both techniques are accepted methods of uterine repair. Technique of repair depends on surgeon's choice and clinical situation. Exteriorization repair is a valid option with no significant increase in morbidity compared to In-situ repair especially in cases where exposure of lower uterine segment is difficult, there is extension of incision and difficulty in achieving hemostasis.

Keywords: Cesarean section, Exteriorization, In-situ repair

\section{INTRODUCTION}

Cesarean section is one of the most commonly performed abdominal operations on pregnant women worldwide and rates of primary cesarean sections are increasing and inturn repeat cesarean sections with increase in both short and long term morbidity. The incidence according to the latest data is $18.6 \%$ of all deliveries were by cesarean section ranging from $6 \%$ to $27.2 \%$ in the least and most developed regions. ${ }^{1}$ It was estimated that approximately 18.5 million cesarean sections are being performed worldwide. The ideal rate for cesarean section according to WHO based report is between $10 \%$ and $15 \%{ }^{2}$

Complications and morbidity depend on the type of hospital, obstetrician, facilities and indications. Many variations in surgical technique have been devised to decrease the adverse effects, post-operative morbidity and 
hospital stay. One such modification is uterine repair after the delivery of the fetus and placenta either by intraabdominal repair or temporarily exteriorizing the uterus on the mother's abdomen and repairing it. There is a controversy as to which type of uterine repair is better.

The present study was done to compare Intra-operative and Post-operative complications of Uterine repair with Exteriorization and In-situ repair.

Aim of the study was to assess the intraoperative and postoperative complications of Exteriorization repair with In-situ repair during caesarean delivery.

\section{Objectives}

- To assess the complications of Exteriorization repair

- To assess the complications of In-situ repair

- To compare the intraoperative and postoperative advantages and disadvantages of these two methods.

\section{METHODS}

This was a prospective comparative study of 200 term pregnant women with singleton live pregnancy with cephalic presentation undergoing elective/emergency cesarean section who were assigned into 2 groups. Group I (Exteriorization) 100 cases and Group II (In-situ group) 100 cases. The study was conducted at Mahatma Gandhi Medical College and Research Institute, Pondicherry during the period of 18 months from March 2015 to August 2016 after obtaining written consent from women who were willing to participate in the study. Ethical clearance was obtained from Institute Ethical Committee.

\section{Inclusion criteria}

Patients undergoing cesarean delivery (Both elective and emergency). Term live singleton pregnancy with cephalic presentation.

\section{Exclusion criteria}

Anemia with $\mathrm{Hb}<8 \mathrm{gm}$, Multiple pregnancy, Antepartum hemorrhage, Diabetes mellitus complicating pregnancy, Preeclampsia and eclampsia, Premature rupture of membrane $>6$ hours, Chorioamnionitis, Malpresentations.

All patients were given 1 gm Cefazoline intramuscularly half an hour before surgery. Lower uterine segment cesarean sections were done by Pfannensteil incision under regional anesthesia.

After the delivery of the foetus, uterine repair was done either by exteriorization repair or in-situ repair in two layers. Intra-operative and post-operative complications were assessed and statistical analysis done using Student's t-test, Chi-square test/Fisher exact test. Statistical significance was assessed at 5\% level of significance (0.05) and a value of 0.001 was taken as highly significant. The statistical software SPSS 15.0 was used for analysis of data.

\section{RESULTS}

200 women who underwent cesarean section were assigned to 2 groups 100 in each and complications were analysed. $85 \%$ of women in group I $91 \%$ in group II were in the age group of $21-30$ and $59 \%$ and $50 \%$ were primigravida in group I and group II respectively and $90 \%$ were emergency cesarean section in both groups.

There was no significant difference in fall of Mean Pulse Rate, Mean Arterial Pressure, Duration of Surgery, Intraoperative pain, Nausea and Vomiting among both groups. The difference in fall of $\mathrm{Hb}$ between pre and postoperative period was 0.727 and 0.896 in group I and II respectively and not statistically significant (0.301). Intraoperative blood loss was more in in-situ group, compared to exteriorization which was highly significant $(\mathrm{p}<0.001)$ (Table 1).

Table 1: Comparison of blood loss between exteriorization group (i) and in-situ group (ii).

\begin{tabular}{|l|ll|ll|}
\hline Blood & Group I & & Group II & \\
\cline { 2 - 5 } $\operatorname{loss}(\mathbf{m l})$ & $\mathbf{\%}$ & No & \% & No \\
\hline $300-500$ & 65 & 65 & 7 & 7 \\
\hline $500-700$ & 28 & 28 & 58 & 58 \\
\hline $700-900$ & 7 & 7 & 32 & 32 \\
\hline$>900$ & 0 & 0 & 3 & 3 \\
\hline Total & $\mathbf{1 0 0 . 0}$ & $\mathbf{1 0 0}$ & $\mathbf{1 0 0 . 0}$ & $\mathbf{1 0 0}$ \\
\hline
\end{tabular}

Blood transfusion rates were high in in-situ group (15\%) compared to $6 \%$ in exteriorization group and was statistically significant $(\mathrm{P}=0.038)$. There was one case of ureteric injury in in-situ group where there was extension of incision involved angle (Table 2). Between exteriorization Group and In-situ Group.

Table 2: Comparison of blood transfusion rates.

\begin{tabular}{|l|lllll|}
\hline Blood & Group I & & Group II & \\
\hline transfusion & \% & No & \% & No \\
\hline Required & 6 & 6 & 15 & 15 \\
\hline Not required & 94 & 94 & 85 & 85 \\
\hline Total & $\mathbf{1 0 0 . 0}$ & $\mathbf{1 0 0}$ & $\mathbf{1 0 0 . 0}$ & $\mathbf{1 0 0}$ \\
\hline
\end{tabular}

Table 3: Comparison of febrile morbidity between exteriorization group (i) and in-situ group (ii).

\begin{tabular}{|l|lllll|}
\hline Febrile & Group I & & Group II & \\
morbidity & \% & No & \% & No \\
\hline Present & 7 & 7 & 16 & 16 \\
\hline Not present & 93 & 93 & 84 & 84 \\
\hline Total & $\mathbf{1 0 0 . 0}$ & $\mathbf{1 0 0}$ & $\mathbf{1 0 0 . 0}$ & $\mathbf{1 0 0}$ \\
\hline
\end{tabular}

Febrile morbidity was more in group II (16\%) compared 
to group I $(7 \%)$ which was statistically significant ( $\mathrm{p}=$ 0.046 ) (Table 3). Incidence of UTI was $18 \%$ and $26 \%$ in group I and II respectively and was not significant $(\mathrm{p}=0.172)$.

Surgical site infection rates were more in group II (15\%) compared to exteriorization group $8 \%$. There was no statistically significant difference in the surgical site infection rates between the two groups with $\mathrm{p}$ - value of 0.121 (Table 4).

Table 4: Comparison of wound infection between exteriorization group (i) and in-situ group (ii).

\begin{tabular}{|l|llll|}
\hline Wound & Group I & Group II \\
\hline infection & \% & No & \% & No \\
\hline Present & 8 & 8 & 15 & 15 \\
\hline Not present & 92 & 92 & 85 & 85 \\
\hline Total & $\mathbf{1 0 0 . 0}$ & $\mathbf{1 0 0}$ & $\mathbf{1 0 0 . 0}$ & $\mathbf{1 0 0}$ \\
\hline
\end{tabular}

No significant differences were observed in incidence of endometritis or duration of hospital stay.

\section{DISCUSSION}

This was a prospective comparative study of 200 women who underwent caesarean delivery and were assigned to two groups, hundred in each group. There was no significant difference with regard to their age, parity, gestational age at cesarean section. Similar distribution was seen in studies reported by Ezechi et al and Das et al. $^{3,4}$

In the present study, the mean drop in pulse, blood pressure was not statistically significant in both groups. Edi-Osagie et al did not find any clinically significant fall in pulse, arterial blood pressure and oxygen saturation between the two groups. In the present study fall in postop $\mathrm{Hb}$ was $0.727 \mathrm{gm} / \mathrm{dl}$ in group I and $0.896 \mathrm{gm} / \mathrm{dl}$ in group II which was not statistically significant. ${ }^{5}$ Zaphiratos et al in their meta-analysis reported that uterine repair by exteriorization reduced the blood loss, less decrease in $\mathrm{Hb}$ levels but the difference was not statistically significant. ${ }^{6}$ Ezechi et al in their randomized study observed postoperative anemia was $21 \%$ in in-situ group and $6.2 \%$ in exteriorization repair which was statistically significant. $^{3}$

Duration of surgery was less than 1hour in $88 \%$ and $81 \%$ of patients in group 1 and group II respectively and not significant. Slight decrease in operating time in exteriorization group was probably due to better visualization of scar and faster repair. Similar findings were reported by Nasir et al and Das et al. However, Shiya et al and El Khayat et al reported that duration of surgery in exterioriztion group was significantly less when compared to in-situ group., ${ }^{4,-9}$
Edi-Osagie et al reported no significant difference in nausea, vomiting and intra-operative pain. ${ }^{5}$ It was similar to our study. El-Khayat et al also found no significant difference in intraoperative pain, nausea and vomiting. ${ }^{9}$ Postoperative pain was moderate to severe and was more in exteriorization group and required additional analgesia. This is probably due to increased stretch on the uterine ligaments and parietal peritoneum.

There was one instance of ureteric injury in a case of angle extension of uterine incision in In-situ group. Exteriorization of uterus results in better visualization of the scar and proper suturing with minimal trauma to bladder and ureter and also helps in finding any adnexal pathology.

In our study amount of blood loss and blood transfusion rates were high in in situ group compared to exteriorization repair which was statistically significant. $15 \%$ in in-situ and $6 \%$ in exteriorization group required blood transfusion. This may be due to better exposure of the lower uterine segment, shorter duration of surgery, reduced blood loss and in-turn decrease in blood transfusion in exteriorization. The other factor for reduction in blood loss is traction pressure on uterus which acts as a tourniquet on uterine vessels. Ezechi et al reported similar results whereas Nasir et al, El Khayat et al, Zaphiratos et al reported no significant difference in blood loss and blood transfusion rates. $3,7,9,6$

In the present study, febrile morbidity was $7 \%$ in group I and $16 \%$ in group II which was statistically significant and UTI was $18 \%$ and $26 \%$ respectively in group I and II and not significant. Das et al reported febrile morbidity of $6 \%$ and $19 \%$ in exteriorization and In-situ group respectively whereas UTI was similar in both groups $(4 \%$ and $5 \%)^{4}$

Edi-Osagie et al found no significant difference in febrile morbidity or UTI between the two groups. ${ }^{5}$

Coutinho et al in their study found surgical site infection in $7 \%$ and endometritis in $1.7 \%$ in exteriorization group compared to $8.7 \%$ and $2 \%$ in In-situ repair group. ${ }^{10}$ Similar observation were reported by El-Khayat et al which were not significant. ${ }^{9}$ In the present study the incidence of surgical site infection was slightly more in In-situ group $15 \%$ compared to $8 \%$ in exteriorization, endometritis was $2 \%$ in exteriorization and more in Insitu group. They were not significant statistically. Duration of hospital stay was similar in both groups in our study. Das et al observed a significant increase in duration of hospital stay in the In-situ group. Magannet et al observed a longer hospital stay in exteriorization group. ${ }^{4,11}$ Edi-Osagie et al found no significant difference in the hospital stay. ${ }^{5}$

Cochrane collaboration systematic review comparing Insitu repair with exteriorization repair found no statistically significant difference in any variables except 
for the lower rate of post-partum fever and shorter hospital stay in exteriorized group and concluded that evidence is not sufficient to suggest any method of uterine repair to be superior to the other. ${ }^{12}$

\section{Limitations}

Small sample size both elective and emergency cesarean sections were performed by different obstetricians.

\section{CONCLUSION}

The ideal surgical technique of uterine repair at cesarean section continues to be controversial. Personal preference and clinical situation should be the main choice as in either technique some data justifies a choice of technique. Exteriorization is a valid option without increasing the morbidity especially in cases where there is a difficulty in visualization of uterine scar and difficulty in achieving hemostasis.

Funding: No funding sources Conflict of interest: None declared

Ethical approval: The study was approved by the Institutional Ethics Committee

\section{REFERENCES}

1. Betrán AP, Ye J, Moller AB, Zhang J, Gülmezoglu AM, Torloni MR. The Increasing Trend in Cesarean Section Rates: Global, Regional and National Estimates: 1990-2014. PLoS one. 2016;11(02).

2. World Health Organisation. WHO statement on cesarean section rates. Geneva: World Health Organisation; 2015.

3. Ezechi OC, Kalu BK, Njokanma FO, Nwokoro CA, Okeke GC. Uterine incision at cesarean section: A randomized comparative study of intraperitoneal closure and closure after temporary exteriorization. West Afr J Med. 2005;24:41-43.

4. Das S, Das P, Mahli A, Biswas S. Comparative study of uterine repair during cesarean sectionIntraabdominal Vs exteriorization of uterus. ISORJDMS. 2015;14(1):05-8.
5. Edi-Osagie EC, Hopkins RE, Ogbo V, LockhatClegg F, Ayeko M, Akpala WO, Mayers FN. Uterine exteriorisation at caesarean section: influence on maternal morbidity. BJOG: An International Journal of Obstetrics and Gynaecology. 1998;105(10):10708.

6. Zaphiratos V, Gorge RB, Boyd JC, Habib AS. Uterine exteriorization compared with in-situ repair for cesarean delivery: a systematic review and metaanalysis. Can J Anesth. 2015;62(11):1209-20.

7. Nasir H, Imran R, Naz I, Saif N. Uterine exteriorization compared with insitu repair at cesarean delivery. Journal of Rawalpindi Medical College. 2011;15(2):110-12.

8. Shiya A, Akhtar S, Khan S. Comparison of intraoperative and post-operative complications of intraabdominal versus extra abdominal uterine repair at cesarean delivery. Pak Armed Forces Med J. 2015;65:191-94.

9. El-Khayat W, Elsharkawi M, Hassan AA. randomized controlled trial of uterine exteriorization versus in-situ repair of the uterine incision during cesarean delivery. Int $\mathrm{J}$ of Gynecol Obstet. 2014;127:163-66.

10. Coutinho IC, Ramos de Amorim MM, Katz L, Bandeira de Ferraz AA. Uterine exteriorization compared with in situ repair at cesarean delivery: a randomized controlled trial. Obstet Gynecol. 2008;111(3):639-47.

11. Magannet EF, Dodson MK, Albert JR. Blood loss at the time of cesarean section by method of placental removal and exteriorization versus in-situ repair of uterine incision. Surg Gynecol Obstet. 1993; 177:389-92.

12. Jacobs-Jokhan D, Hofmeyr G. Extra-abdominal versus intra-abdominal repair of the uterine incision at cesarean section. The Cochrane database of systematic reviews; 2004;4.

Cite this article as: Lakshmi $\mathrm{P}$, Reddi RP, Lopamudra B. Comparative study of uterine repair during caesarean section: exteriorization repair versus in-situ repair. Int J Reprod Contracept Obstet Gynecol 2017;6:1426-9. 